Pure \& Appl. Chem., Vo1 56, No. 12, pp 1767-1779, 1984. Printed in Great Britain.
$0033-4545 / 84 \$ 3.00+0.00$ Pergamon Press Ltd.

(C) 1984 IUPAC

\title{
KINETIC STUDIES OF SOME FREE RADICAL REACTIONS
}

\author{
Keith U. Ingold \\ Division of Chemistry, National Research Council of Canada \\ Ottawa, Ontario KIA OR6, Canada
}

\begin{abstract}
Kinetic and mechanistic studies on some characteristic free radical reactions are reviewed briefly. The unimolecular rearrangements: $\mathrm{RCMe}_{2} \mathrm{CH}_{2}^{\circ} \rightarrow \mathrm{Me}_{2} \mathrm{C} \mathrm{CH}_{2} \mathrm{R}$, fall into two classes. Class $1: R=R^{\prime} C(0) 0$ for which the 1,2-migration occurs via a 5-center cyclic transition state with considerable charge separation, $\left[\mathrm{R}^{\prime} \mathrm{CO}_{2}^{-} \mathrm{Me}_{2} \mathrm{CCH}_{2}^{+}\right]^{\ddagger}$. $\mathrm{Class} 2$ : $\mathrm{R}=\mathrm{H}_{2} \mathrm{C}=\mathrm{CH}, \mathrm{Me}_{3} \mathrm{CC}=0, \mathrm{C}_{6} \mathrm{H}_{5}, \mathrm{Me}_{3} \mathrm{CC} \equiv \mathrm{C}$, and $\mathrm{C} \equiv \mathrm{N}$, for which migration occurs via a 3-center transition state; at $25^{\circ} \mathrm{C}$ rate constants for the migrations of these groups are: $1 \times 10^{7}$, $2 \times 10^{5}, 780,95$, and $1 \mathrm{M}^{-1} \mathrm{~s}^{-1}$, respectively. Non-planar group IV centered radicals can rearrange by inversion; rate constants for inversion of $\mathrm{Si}$ - and Ge-centered radicals have been estimated. A very common radical reaction is $\mathrm{H}$-atom abstraction, a process which may involve quantum-mechanical tunneling. The reaction: $\left(\mathrm{CF}_{3}\right)_{2} \mathrm{NO}^{\circ}+\mathrm{RH} \rightarrow\left(\mathrm{CF}_{3}\right)_{2} \mathrm{NOH}+\mathrm{R}^{\circ}$, has been studied in solution in Freon at temperatures from 190 to $300 \mathrm{~K}$ for a variety of $\mathrm{RH}$.
\end{abstract} Although the Arrhenius pre-exponential factors are unexpectedly low (e.g., $10^{5.8} \mathrm{M}^{-1} \mathrm{~s}^{-1}$ for cyclopentane), no evidence for tunneling was obtained. In contrast, the decay of $\mathrm{CH}_{3}^{\circ}$ in methanol glasses is controlled by tunneling. This decay follows a rate law of the form $\exp \left(-c t^{\frac{1}{2}}\right)$, which we attribute to a distribution of exponential decays which arise from the inhomogeneity of the matrix, and analyze by the method of inverse Laplace transforms. Rate constants calculated using a physically realistic model and with the few "adjustable" parameters confined to realistic values are in excellent agreement with experiment for $\mathrm{CH}_{3}^{\circ}+\mathrm{CH}_{3} \mathrm{OH}$ from 5 to $97 \mathrm{~K}$ and for $\mathrm{CH}_{3}^{\circ}+\mathrm{CD}_{3} \mathrm{OD}$ from 77 to $97 \mathrm{~K}$.

\section{INTRODUCTION}

Kinetic studies of free radical reactions in solution have reached a mature stage in their development. Many different time-resolved techniques are now available for measuring the absolute rates of all types of elementary reactions. The three techniques that have been most widely employed are the rotating sector method (RSM), kinetic electron paramagnetic resonance spectroscopy (KEPRS), and kinetic absorption spectroscopy (KAS). These techniques have become popular because they are exceptionally versatile in terms of the types of radicals, the range of reaction classes, and the range of reaction rates that can be investigated. They are also versatile as regards the nature of the solvent and the range of temperature that can be used. These three techniques, as well as others that are more specialized, are complementary, not competitive. That is, one technique is not intrinsically "better" than another, it is merely more suited to the study of particular groups of elementary reactions. On those rare occasions when two independent procedures have been applied to the same reaction the kinetic data have generally been in agreement. Confidence in both techniques is thereby enhanced. An up-to-date, comprehensive listing of absolute kinetic data for free radical reactions in solution that have been obtained by timeresolved methods fills several volumes (1).

Directly measured absolute rate constants form the primary kinetic standards in free radical chemistry. Secondary standards are obtained by competitive kinetic procedures. These secondary standards can then be employed in further competitive experiments to obtain additional "absolute" rate data. During the past 25 years the successful marriage of timeresolved and competitive kinetic measurements has begat an enormous volume of quantitative kinetic information about the reactions of free radicals in solution. Indeed, to the uninitiated it might appear that every rate constant of any conceivable interest has been measured. This is not the case as I have been told countless times by frustrated chemists who have vainly searched the free radical literature for the magic number that will allow them to quantify their experimental results. (On some occasions, I have even been made to feel as though I were personally responsible for the lack of the required rate constant.)

For this talk I intend to ignore methodology since this is of interest only to specialists. Instead, I am going to pick out and briefly describe some of our more recent kinetic and 
mechanistic investigations. The reactions I have chosen will, I hope, prove interesting to physical organic chemists and should fit the conference theme of 'intermediates and transition states in organic reactions'.

\section{RADICAL REARRANGEMENTS}

Radical rearrangements are of growing importance in general studies of organic reaction mechanisms. This is because the presence of radical intermediates in a reaction of uncertain mechanism can frequently be probed by using as the potential intermediate a species that, if it is a free radical, will undergo an irreversible and unequivocal rearrangement (2). Once radicals have been implicated in a reaction, the next step is to use as a probe a species that will undergo rearrangement at a known rate and, furthermore, at a rate that is competitive with the rate of the elementary step in which the radical is involved; this allows the rate of the elementary step to be determined. Radicals that undergo rearrangements at known rates have been dubbed "free radical clocks" because they can be used to "time" the rates of radical/molecule reactions (3). For each class of radicals a fairly large family ("horlogerie" (3)) of clocks is required since some are needed to time fast reactions and others to time slow reactions.

The most complete horlogerie is that for primary alkyl radicals (3). That is, a wide variety of primary alkyls have been found to undergo rearrangement and have had the rates of their rearrangement measured. A particularly interesting and potentially useful subgroup of primary alkyl clocks on which we have been working for many years is described below.

\section{REARRANGEMENT OF $\mathrm{RCMe}_{2} \mathrm{CH}_{2}^{\bullet}$ RADICALS}

These rearrangements involve the 1,2-migration of an unsaturated $R$ group from the quaternary carbon to the primary carbon:

$$
\begin{array}{cc}
\mathrm{RCMe}_{2} \mathrm{CH}_{2}^{\cdot} \longrightarrow \\
1
\end{array}
$$

Such rearrangements fall into two distinct mechanistic classes.

\section{Class 1. The $\beta$-(Acyloxy)alkyl rearrangement}

The 1,2-migration of $R^{\prime} C(0) 0$ groups has provided a fascinating mechanistic puzzle to chemists, in part because the reaction has no direct intermolecular analogue.<smiles></smiles>

This class of rearrangements was first observed in 1967 (4). Later it was suggested (5) that the reaction proceeded through the 1,3-dioxolan-2-yl radical, 5, which could serve as "a transition state, or an unreactive intermediate". Subsequent kinetic and product studies by Beckwith $(6,7)$ led to the conclusion that 5 did not lie on the rearrangement pathway, although labelling experiments with ${ }^{18} 0$ showed a clean inversion of the positions of the two acyloxy oxygens. A cyclic transition state of 111 -defined structure, 6 , was proposed (7).<smiles>[R]C1OC[C@@H]1O</smiles>

5<smiles>[R]C1=C2CC(=CO2)O1</smiles>

6

The evidence that 5 was not involved in these rearrangements came from kinetic studies in water (6) where it was found that $3\left(R^{\prime}=M e\right)$ underwent rearrangement to $4\left(R^{\prime}=M e\right)$ 
more rapidly than $5\left(R^{\prime}=M e\right)$, generated independently from the parent 2,4,4-trimethyl1,3-dioxolan, underwent rearrangement to the same product, reaction 3 .

$$
5 \longrightarrow 4
$$

A one-step concerted rearrangement was therefore proposed but the question as to the essential difference between 5 and 6 remained unanswered.

Our own KEPRS studies in hydrocarbon solvents (8) showed that with $R^{\prime}=$ Me reaction 2 was slower than reaction 3 , e.g., $k_{2}^{75^{\circ} \mathrm{C}}=5 \times 10^{2} \mathrm{~s}^{-1}$ while $k_{3}^{75^{\circ} \mathrm{C}}=8 \times 10^{3} \mathrm{~s}^{-1}$. Therefore, no mechanistic conclusions were possible. However, with $R^{\prime}=$ cyclopropyl 3 underwent

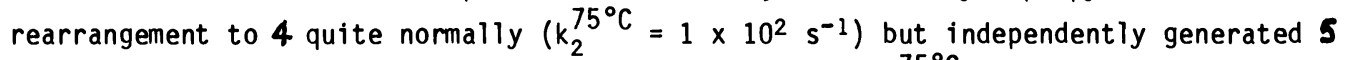

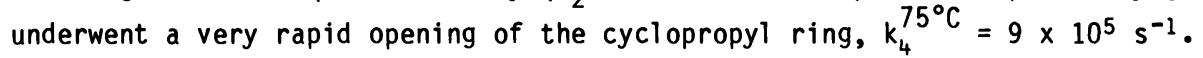

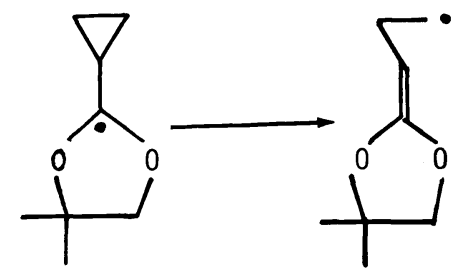

This result served to confirm Beckwith's conclusion that 5 could not lie on the $3+4$ reaction pathway. Values of ca. $10^{13} \mathrm{~s}^{-1}$ were found for the Arrhenius pre-exponential factors for reaction 2, which suggested that its transition state must be relatively "loose" with C-0 bond stretching virtually complete before there has been much bond making between the carboxyl oxygen and the primary radical center (8). We therefore proposed that a charge-separated structure, 7 , played an important role in the $3+4$ transition state (8).

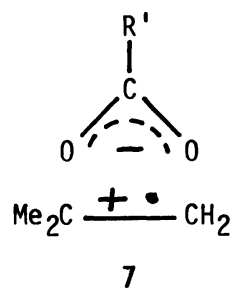

Support for this proposal comes from our more recent KEPRS studies (9). We hypothesized that an inductively electron-attracting $R^{\prime}$ group would strongly accelerate the $3+4$ rearrangement because it should stabilize the transition state 7 , whereas such a group would probably reduce the rate of the $5+4$ rearrangement because of the general strengthening of $\sigma$ bonds that is produced by electron withdrawal. We also hypothesized that the $3 \rightarrow 4$ rearrangement should be accelerated by polar solvents since they too should stabilize the transition state 7. Both hypotheses have been tested and confirmed (9). Thus, in non-polar solvents with $R^{\prime}=C F_{3}$ (a strong -I group) reaction 2 was much faster $\left(k_{2}^{75^{\circ} \mathrm{C}}=7 \times 10^{4} \mathrm{~s}^{-1}\right)$ than had been found for $\mathrm{R}^{\prime}=\mathrm{Me}$, while reaction 3 became too slow to measure $\left(k^{120^{\circ} \mathrm{C}}<\mathrm{ca} .10^{2} \mathrm{~s}^{-1}\right)$; clearly for $\mathrm{R}^{\prime}=\mathrm{CF}_{3}$ the dioxolanyl radical 5 cannot lie on the rearrangement pathway. Similarly, with $R^{\prime}=$ Me in water reaction 2 was much faster $\left(k_{2} 75^{\circ} \mathrm{C}=2 \times 10^{4} \mathrm{~s}^{-1}\right)$ than was the case in non-polar solvents. A dipolar transition state for the 1,2-migration of acyloxy groups would seem to be firmly established by experiment (9) and it has recently received further support via ab initio M0 calculations (10).

Class 2. The neophyl and related rearrangements

The first free radical rearrangement to be discovered was reported by Urry and Kharasch in 1944 (11). It was, of course, the neophyl rearrangement, reaction $1(R=P h)$.

$$
\begin{aligned}
& \mathrm{RCMe}_{2} \mathrm{CH}_{2} \longrightarrow \mathrm{Me}_{2} \mathrm{CCH}_{2} \mathrm{R} \\
& 12 \\
& \text { R: a, } \mathrm{C}_{6} \mathrm{H}_{5} ; \mathrm{b}, \mathrm{Me}_{3} \mathrm{C} \equiv \mathrm{C} ; \mathrm{c}, \mathrm{CH}_{2}=\mathrm{CH} ; \mathrm{d}, \mathrm{Me}_{3} \mathrm{CC}=0 \text {; e, } \mathrm{C} \equiv \mathrm{N}
\end{aligned}
$$


We have used KEPRS to measure Arrhenius parameters for the neophyl rearrangement, $1 \mathbf{a}+2 \mathbf{2 a}$ (12); for a homopropargylic rearrangement, $1 b+2 b(13)$; and for a homoallylic rearrangement, $1 c+2 c(14)$. These, as well as the other two rearrangements, are intramolecular processes there being no evidence that would favor the alternative dissociation-readdition mechanism (15):

$$
\mathrm{RCMe}_{2} \mathrm{CH}_{2}^{\cdot} \longrightarrow \mathrm{R}^{\bullet}+\mathrm{Me}_{2} \mathrm{C}=\mathrm{CH}_{2} \longrightarrow \mathrm{Me}_{2}{ }_{2} \mathrm{CCH}_{2} \mathrm{R}
$$

Each of the five indicated rearrangements must occur via a short lived, 3-membered cyclic intermediate or transition state (15).

To gain a better understanding of the factors that control $R$ migration rates we have recently measured relative migratory aptitudes in la - le by a competitive procedure

(15). Radicals 1 were generated by $\mathrm{H}$-atom abstraction from the parent compound $\mathrm{RCMe}_{3}$ (1H) with tert-butoxyl radicals in the presence of $\mathrm{CCl}_{4}$. Rates of rearrangement were measured relative to the rates of reaction of 1 with $C_{\ell_{4}}$ by analyses of the relative yields of the monochloride products, $1 C_{\ell}$ and $2 \mathrm{C}_{\ell}$, at known $\mathrm{CC}_{\ell_{4}}$ concentrations.

$$
\begin{aligned}
& \mathrm{RCMe}_{2} \mathrm{CH}_{2}^{\cdot}+\mathrm{CCl}_{4} \longrightarrow \mathrm{K}_{\ell} \longrightarrow \mathrm{RCMe}_{2} \mathrm{CH}_{2} \mathrm{Cl}+\mathrm{CCl}_{3}^{\cdot} \\
& 1 \quad 1 \mathrm{Cl}
\end{aligned}
$$

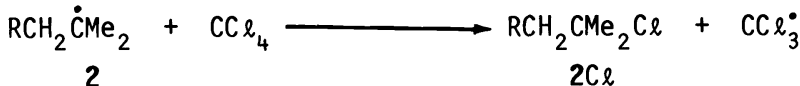

Since the $R$ group in 1 is remote from the radical center it is reasonable to assume that $k_{C}$ will be independent of the nature of $R$. Relative Arrhenius parameters for rearrangement vs. chlorine abstraction have been determined for $1 \mathbf{a}, \mathbf{1 b}, \mathbf{1 d}$, and $\mathbf{1 e}$. Radical 1c underwent rearrangement so rapidly that none of the unrearranged chloride, $1 \mathrm{cCl}$, could be detected among the products; this was an expected result since we had previously shown that the $1 c+2 c$ rearrangement is extraordinarily fast (14).

Conversion of the relative rate data to an absolute scale requires knowledge of the absolute Arrhenius parameters for chlorine atom abstraction from $\mathrm{CC}_{\ell_{4}}$ by a primary alkyl radical (reaction 5). Unfortunately, reliable Arrhenius parameters for this reaction were not available. We therefore had to choose one of the $1+2$ rearrangements as our primary standard. We picked the neophyl rearrangement but did not use the KEPRS rate data because the reported activation energy (12) is probably too large by ca. $2 \mathrm{kcal} / \mathrm{mol}(15)$. Instead, we used an Arrhenius equation derived by Franz and coworkers (16) from a study of the relative yields of $1 \mathrm{aH}$ and $2 \mathrm{aH}$ formed during the reduction of neophyl chloride, $\mathrm{laCl}$, by $\mathrm{n}-\mathrm{Bu}_{3} \mathrm{SnH}$.

$$
\begin{aligned}
& 1 \mathrm{aCl}+\mathrm{n}-\mathrm{Bu}_{3} \mathrm{Sn} \longrightarrow \mathrm{a}+\mathrm{a}+\mathrm{n}-\mathrm{Bu}_{3} \mathrm{SnCl} \\
& 1 \mathrm{a}+\mathrm{n}-\mathrm{Bu}_{3} \mathrm{SnH} \longrightarrow \mathrm{aH}+n-\mathrm{Bu}_{3} \mathrm{Sn} \\
& 2 \mathrm{a}+\mathrm{n}-\mathrm{Bu}_{3} \mathrm{SnH} \longrightarrow 2 \mathrm{aH}+\mathrm{n}-\mathrm{Bu}_{3} \mathrm{Sn}
\end{aligned}
$$

The Arrhenius equation of Franz et al for the $1 a+2 a$ rearrangement (see Table I) necessarily was based on the "absolute" Arrhenius equation measured in our laboratory by KAS for $\mathrm{H}$-atom abstraction from $\mathrm{n}-\mathrm{Bu}_{3} \mathrm{SnH}$ by a primary alkyl radical (17) (i.e., for a reaction analogous to 9 ). Incidentally, our confidence in this KAS measurement as our primary standard is strengthened by the fact that it confirmed an earlier RSM measurement of the room temperature rate constant from the reaction of a primary alkyl radical with n$\mathrm{Bu}_{3} \mathrm{SnH}(18)$.

Preferred Arrhenius parameters as well as rate constants at $25^{\circ} \mathrm{C}$ for five $1+2$ rearrangements are given in Table $I$. The parameters for the $1 a+2 a$ rearrangement, which were obtained as described above, were combined with our measurements of $1 \mathrm{aCl} / 2 \mathrm{aCl}$ ratios to obtain the Arrhenius equation for chlorine atom abstraction from $\mathrm{CCl}_{4}, \mathrm{viz}$.

$$
\log \left(\mathrm{k}_{C_{l}} / \mathrm{M}^{-1} \mathrm{~s}^{-1}\right)=8.11-5.45 /(2.3 \mathrm{RT} \mathrm{kCal} / \mathrm{mol}) .
$$

The parameters for rearrangement of $1 \mathrm{~b}, \mathbf{1 d}$, and $1 \mathrm{e}$ were calculated using this equation.

The order of the migratory aptitudes of the various $\mathrm{R}$ groups, viz. $\mathrm{H}_{2} \mathrm{C}=\mathrm{CH}>\mathrm{Me}_{3} \mathrm{CC}=0>\mathrm{Ph}>$ $\mathrm{Me}_{3} \mathrm{CC} \equiv \mathrm{C}>\mathrm{N} \equiv \mathrm{C}$, is somewhat unexpected since we tend to think that the 40 year old neophyl rearrangement must be a fairly rapid process, which it certainly is not. Rates of migration of these groups are determined primarily by their activation energies which increase 
dramatically on going from $R=H_{2} C=C H$ to $R=N \equiv C$. The presumption that the rate determining step lies in the formation of a 3-membered ring, $i . e$. , structure 8 for $R=$ $X=C Y$, can (in theory) be checked by comparing $E_{r}$ with the calculated endothermicities for

TABLE 1. Preferred kinetic data for five $\mathrm{RCMe}_{2} \mathrm{CH}_{2} \longrightarrow \mathrm{Me}_{2} \dot{\mathrm{CCH}}_{2} \mathrm{R}$ rearrangements

\begin{tabular}{lccc}
\hline$R$ & $\log \left(\underline{A}_{r} / \mathrm{s}^{-1}\right)$ & $\begin{array}{c}E_{r} \\
(\mathrm{kcal} / \mathrm{mol})\end{array}$ & $\begin{array}{c}\mathrm{k}_{r}^{25}{ }^{\circ} \mathrm{C} \\
\left(\mathrm{s}^{-1}\right)\end{array}$ \\
\hline $\mathrm{Ph}$ & 11.5 & 11.8 & 780 \\
$\mathrm{Me}_{3} \mathrm{C} \equiv \mathrm{C}$ & 11.3 & 12.7 & 95 \\
$\mathrm{H}_{2} \mathrm{C}=\mathrm{CH}$ & 11.2 & 5.7 & $1 \times 10^{7}$ \\
$\mathrm{Me}_{3} \mathrm{CC}=0$ & 10.9 & 7.7 & $2 \times 10^{5}$ \\
$\mathrm{~N} \equiv \mathrm{C}$ & 12.0 & 16.4 & 1 \\
\hline
\end{tabular}

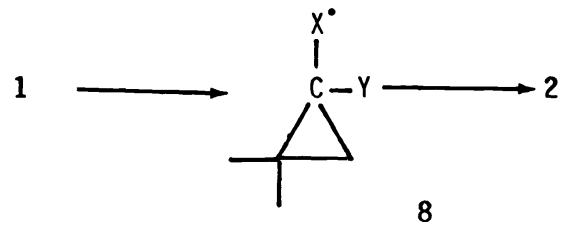

ring closure of 1 using thermochemical data and group additivity principles. Unfortunately, much of the required data are either unknown or are of questionable accuracy. The most reliable data relate to the cyclization of $1 \mathrm{c}$ which can be calculated to be endothermic by $6-7 \mathrm{kcal} / \mathrm{mol}$, which is in satisfactory agreement with experiment. The minimum calculated endothermicity for the cyclization of la is $11 \mathrm{kcal} / \mathrm{mol}$, but a more probable value would be several $\mathrm{kcal} / \mathrm{mol}$ larger. Thermochemical calculations for $1 \mathrm{~b}$ and $1 \mathrm{~d}$ suggest minimum endothermicities for cyclization of 18 and $22 \mathrm{kcal} / \mathrm{mol}$, respectively, while for le the endothermicity cannot be calculated. We attribute the fact that minimum estimated endothermicities for most $1+2$ rearrangements are greater than the experimental activation energies to the relief of steric compression which accompanies formation of a gem-dialkyl substituted 3-membered ring (the Thorpe-Ingold effect). Current thermochemical calculations do not reflect such steric factors adequately. We consider that Thorpe-Ingold effects provide the most likely explanation for the unexpectedly low activation energies for the rearrangements of $1 \mathrm{a}, 1 \mathrm{~b}$ and $1 \mathrm{~d}$. However, we do not rule out the possibility that one or more of these reactions proceed in a concerted manner with the 3-membered ring being a transition state rather than a discrete, though short lived intermediate.

\section{INVERSION OF NON-PLANAR GROUP IV-CENTERED RADICALS}

Most silicon- and germanium-centered radicals are non-planar. Carbon-centered radicals are also non-planar if the substituents attached to the radical center are strongly electron-withdrawing, e.g., $\mathrm{CF}_{3}^{\circ}$, or if the radical-center is part of a 3-membered ring, e.g., cyclopropyl. The rates of inversion of such radicals can be determined if the inversion process can be made to compete with an intermolecular reaction which has a known rate constant. We have employed this procedure to calculate some of the first chemically interesting radical inversion frequencies.

We have measured rate constants by KAS for the reactions of triorganosilyl (19) and triorganogermyl (20) radicals with a variety of substrates including, in particular, $\mathrm{CC}_{\ell_{4}}$. The significance of these measurements arises from the fact that when the (1-naphthyl) phenylmethylsilyl radical (21) or the analogous germyl radical (22) were generated from optically active precursors in the presence of $\mathrm{CCl}_{4}$ the degree of optical purity in the products was dependent on the $\mathrm{CC}_{\ell_{4}}$ concentration. 


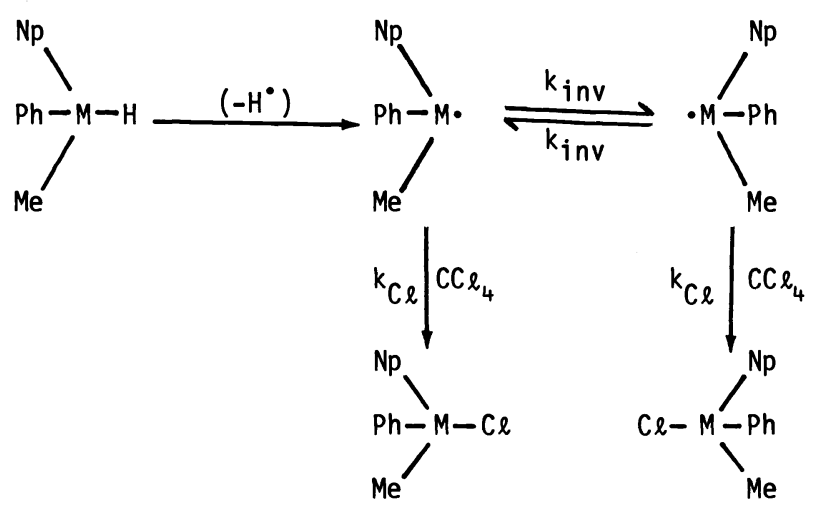

This reaction scheme can be described by the equation:

$$
\frac{1}{\text { optical purity }}=\alpha+\alpha \frac{k_{\text {inv }}}{k_{C_{\ell}}} \frac{1}{\left[\mathrm{CC}_{l_{4}}\right]}
$$

where $\alpha$ is an arbitrary constant. Combining our measurements of $k_{C l}$ with the reported optical purity data yielded the results summarized in Table 2.

TABLE 2. Inversion of optically active $\mathrm{Np}(\mathrm{Ph})(\mathrm{Me}) \mathrm{M}^{\bullet}$ radicals

\begin{tabular}{cccc}
\hline $\mathrm{M}$ & $\mathrm{kinv}_{\text {inv }}^{80} \mathrm{C}$ & $\begin{array}{c}\log \left(\mathrm{A}_{\text {inv }} / \mathrm{s}^{-1}\right) \\
(\text { assumed })\end{array}$ & $\begin{array}{c}\mathrm{E}_{\text {inv }} \\
(\mathrm{kcal} / \mathrm{mol})\end{array}$ \\
\hline $\mathrm{Si}$ & $7 \times 10^{9}$ & 13.3 & 5.6 \\
$\mathrm{Ge}$ & $1 \times 10^{9}$ & 13.3 & 7.0 \\
\hline
\end{tabular}

A similar experimental approach is currently being employed in our laboratory in an attempt to determine the inversion frequency of the cyclopropyl radical and of $\alpha$-substituted cyclopropyl radicals stereospecifically labelled with deuterium $(23,24)$.

\section{A SEARCH FOR QUANTUM-MECHANICAL TUNNELING IN AN INTERMOLECULAR H-ATOM TRANSFER}

Several years ago we showed that 2,4,6-tri-tert-butylphenyl decayed by an intramolecular $\mathrm{H}$-atom migration and that quantum-mechanicat tunneling played an important role in the reaction $(25,26)$.<smiles>CC(C)(C)c1cc(C(C)(C)C)cc(C(C)(C)C)c1</smiles>

Quantum-mechanical tunneling has also been shown to be important in intermolecular $\mathrm{H}$-atom abstractions in solid matrices at low temperatures (see following section). In both the intramolecular and these intermolecular processes a limited number of hydrogen atoms surround each radical center and the radical eventually reacts with one of these hydrogens, since there is no other pathway by which it can decay.

Convincing evidence for q.m. tunneling has not yet been presented for any intermolecular $\mathrm{H}$-atom abstraction in solution. This is understandable because considerable difficulties must be overcome if tunneling is to be unequivocally identified. Detailed study of the reaction:

$$
\mathrm{X}^{\bullet}+\mathrm{RH} \longrightarrow \mathrm{XH}+\mathrm{R}^{\bullet}
$$


by KEPRS requires the following: (i) $X^{\bullet}$ must be observable by EPR; (ii) $X^{\bullet}$ must react only with $R H$, $i . e$. , there must be no bimolecular self-reaction of $x^{*}$, no unimolecular reaction, and no reaction with solvent; (iii) the reaction must be irreversible; (iv) the solvent must have a low freezing point (since tunneling is most readily identified at low temperatures) and should be liquid over a wide range of temperatures.

Consideration of these requirements led us eventually to study the reactions of bis(trifluoromethyl) aminoxyl, i.e., $X=\left(\mathrm{CF}_{3}\right){ }_{2} \mathrm{NO}^{\circ}$, with various organic compounds in Freon solvents (27-29). This remarkable radical, which is a purple gas at room temperature, is both more persistent and more reactive than the better known di-tert-alkylaminoxyls. It does not react with Freon solvents and is monomeric except at high concentrations and low temperatures. The kinetics of $\left(\mathrm{CF}_{3}\right){ }_{2} \mathrm{NO}^{\circ}$ decay in the presence of suitable $\mathrm{H}$-atom donors can therefore be readily monitored by KEPRS. With properly chosen experimental conditions (29) the overall process can be represented by just two reactions:

$$
\begin{aligned}
& \left(\mathrm{CF}_{3}\right)_{2} \mathrm{NO}^{\circ}+\mathrm{RH} \longrightarrow\left(\mathrm{CF}_{3}\right)_{2} \mathrm{NOH}+\mathrm{R}^{\circ} \\
& \left(\mathrm{CF}_{3}\right)_{2} \mathrm{NO}^{\circ}+\mathrm{R}^{\bullet} \longrightarrow\left(\mathrm{CF}_{3}\right)_{2} \mathrm{NOR}
\end{aligned}
$$

Kinetic parameters, which were determined by measurements over a temperature range from ca. 190 to $300 \mathrm{~K}$, are given in Table 3 for some of the substrates that have been examined.

TABLE 3. Kinetic parameters for the reaction: $\left(\mathrm{CF}_{3}\right)_{2} \mathrm{N0^{ \bullet }}+\mathrm{RH}(\mathrm{D})+\left(\mathrm{CF}_{3}\right)_{2} \mathrm{NOH}(\mathrm{D})+\mathrm{R}^{\bullet}$

\begin{tabular}{lccc}
\hline \multicolumn{1}{c}{ RH } & $\log \left(\mathrm{A} / \mathrm{M}^{-1} \mathrm{~s}^{-1}\right)$ & $E(\mathrm{kcal} / \mathrm{mol})$ & $k^{25^{\circ} \mathrm{C}\left(\mathrm{M}^{-1} \mathrm{~s}^{-1}\right)}$ \\
\hline Cyclopentane & 5.8 & 10.7 & 0.01 \\
$1,4-$ Cyclohexadiene & 6.5 & 5.7 & 200 \\
Benzaldehyde & 5.3 & 6.9 & 2 \\
Benzaldehyde-d 6 & 5.1 & 8.2 & 0.1 \\
Diethylether & 4.2 & 7.0 & 0.1 \\
Tri-t-butyl phenol & 4.8 & 3.3 & 240 \\
Tri-n-butylstannane & 5.9 & 4.3 & 550 \\
\hline
\end{tabular}

The Arrhenius pre-exponential factors for all $\left(\mathrm{CF}_{3}\right)_{2} \mathrm{NO}^{\circ}$ reactions are very much lower than the value of $10^{8.5} \pm 0.5 \mathrm{M}^{-1} \mathrm{~s}^{-1}$ that is generally considered "normal" for H-atom abstraction by free radicals (30). However, the kinetic data should be reliable and the Arrhenius plots are linear over the wide range of temperatures employed. Low A-factors are a feature of $\mathrm{H}$-atom transfer reactions in which q.m. tunneling plays a significant role. (This is because tunneling through the potential energy barrier becomes relatively more important, compared with the classical passage over the top of the barrier, as the temperature is lowered.) Nevertheless, the low A-factors cannot be attributed to tunneling for three reasons. (i) The deuterium kinetic isotope effect for $\mathrm{C}_{6} \mathrm{H}_{5} \mathrm{CHO}$ vs. $\mathrm{C}_{6} \mathrm{D}_{5} \mathrm{CDO}$ shows none of the unusual features $\left(k_{H} \gg k_{D}, A_{D}>A_{H}\right.$, etc.) commonly attributed to tunneling. (ii) Tunneling can only occur between states of equal energy which, for practical purposes, excludes endothermic process. (The $\mathrm{O}-\mathrm{H}$ bond strength in $\left(\mathrm{CF}_{3}\right)_{2} \mathrm{NOH}$ is $\mathrm{Ca} .85 \mathrm{kcal} / \mathrm{mol}$ (29) which means that many of the reactions would be appreciably endothermic, most notably cyclopentane for which the $\mathrm{C}-\mathrm{H}$ bond strength is ca. $96 \mathrm{kcal} / \mathrm{mol}$.) (iii) The pre-exponential factor for the addition of $\left(\mathrm{CF}_{3}\right)_{2} \mathrm{NO}^{\circ}$ to $\mathrm{CH}_{2}=\mathrm{CCl}_{2}$, which certainly does not involve an $\mathrm{H}-$ atom transfer, was found to be $10^{5.3} \mathrm{M}^{-1} \mathrm{~s}^{-1}$ which is also appreciably smaller than the values "normal" for radical-molecule addition reactions (ca. $10^{8.5} \mathrm{M}^{-1} \mathrm{~s}^{-1}(30)$ ).

We believe that the $\left(\mathrm{CF}_{3}\right)_{2} \mathrm{NO}^{\circ}$ reactions have "low" A-factors because reaction can occur only via transition states that have a highly restrictive geometry that demands a very specific orientation of the $\left(\mathrm{CF}_{3}\right)_{2} \mathrm{NO}^{\circ}$ relative to the $\mathrm{C}-\mathrm{H}$ (or $\mathrm{C}=\mathrm{C}$ ) bond under attack. It is important to note that the usual assumption that Arrhenius pre-exponential factors for radical/molecule reactions in solution will have "normal" (gas phase) values is not valid for at least one radical.

One quite unexpected result was that the absolute reactivities in $\mathrm{H}$-atom abstraction of 
$\left(\mathrm{CF}_{3}\right)_{2} \mathrm{NO}^{\circ}$ and of the tert-butylperoxyl radical were remarkably similar at ambient temperatures, i.e., this is the isokinetic temperature for reactions 15 and 17 . The relation

$$
\mathrm{Me}_{3} \mathrm{COO}^{\circ}+\mathrm{RH} \longrightarrow \mathrm{Me}_{3} \mathrm{COOH}+\mathrm{R}^{\bullet}
$$

$k_{15} \approx k_{17}$ at $\mathrm{ca} .25^{\circ} \mathrm{C}$ holds for substrates for which the absolute rate constants range from $10^{-2} \mathrm{M}^{-1} \mathrm{~s}^{-1}$ to $10^{2} \mathrm{M}^{-1} \mathrm{~s}^{-1}$ and, after statistical correction for the number of "active" hydrogens in each $\mathrm{RH}$, the kinetic data can be correlated with R-H bond strengths (in $\mathrm{kcal} / \mathrm{mol}$ ) via the equation:

$$
\log \left(k_{17}^{R H} \text { per active } H / M^{-1} \mathrm{~s}^{-1}\right)=15.4-0.2 \mathrm{D}[\mathrm{R}-\mathrm{H}]
$$

The thermochemistries for $\mathrm{H}$-atom abstraction by these two radicals are slightly different (viz. $\mathrm{D}\left[\mathrm{Me}_{3} \mathrm{COO}-\mathrm{H}\right]=88.5 \mathrm{kcal} / \mathrm{mol}, \mathrm{D}\left[\left(\mathrm{CF}_{3}\right)_{2} \mathrm{NO}-\mathrm{H}\right]=85.3 \mathrm{kcal} / \mathrm{mol}$ ) but the spin densities at the radical centers are very similar (viz. $\underline{a}^{170}=23.4_{5} \mathrm{G}$ for $\mathrm{Me}_{3} \mathrm{CO}^{17} 0^{\circ}$ and $23.6 \mathrm{G}$ for $\left.\left(\mathrm{CF}_{3}\right)_{2} \mathrm{~N}^{17} 0^{\circ}\right)$. For those $\mathrm{RH}$ for which kinetic measurements have been made over a range of temperatures for both radicals $A_{15}<A_{17}$ and $E_{15}<E_{17}$. The $\left(C_{3}\right)_{2} \mathrm{NO}^{\circ}$ radical is therefore less reactive than $\mathrm{Me}_{3} \mathrm{COO}^{\circ}$ at high temperatures and more reactive at low temperatures.

\section{KINETICS OF METHYL RADICAL DECAY IN METHANOL GLASSES}

Our failure to observe q.m. tunneling for an intermolecular H-atom abstraction in solution under highly favorable conditions led us to reexamine the decay of methyl radicals in a methanol glass.

$$
\mathrm{CH}_{3}^{\cdot}+\mathrm{CH}_{3} \mathrm{OH} \longrightarrow \mathrm{CH}_{4}+\mathrm{HOCH}_{2}^{\cdot}
$$

This intermolecular matrix reaction has been studied extensively (31-37) and has generally been considered to provide an outstanding example of hydrogen tunneling (31-33). This interpretation was based on the assumption that the reaction follows first order kinetics, $i$.e., that the methyl radical concentration decays according to exp $(-k t)$. However, it has been convincingly demonstrated (34-37) that the decay actually follows a rate law of the form $\exp \left(-c t^{\frac{1}{2}}\right)$. The meaning of the constant $c$ in this expression had not been made clear, since no plausible kinetic scheme supporting such a rate law had been put forward.

We have recently shown that the nonexponential decay of the methyl radical in a methanol glass is due to inhomogeneity of the matrix which produces a superposition of a distribution of exponential decays, each with a different site in the glass (38). Methyl radicals were generated from methyl halides by dissociative electron capture, the electrons being produced by the photoionization of diphenylamine, and their decay was monitored by KEPRS.

$$
\mathrm{CH}_{3} \mathrm{X}+\mathrm{e}^{-} \longrightarrow \mathrm{CH}_{3}^{*}+\mathrm{X}^{-}
$$

In agreement with earlier observations (34-37) a plot of $\ell n\left(\left[\mathrm{CH}_{3}^{\bullet}\right]_{t} /\left[\mathrm{CH}_{3}^{\bullet}\right]_{0}\right)$ against $\mathrm{t}^{\frac{1}{2}}$ was linear for methyl radicals generated by a $10 \mathrm{sec}$ irradiation at $77 \mathrm{~K}(38)$. However, these plots became distinctly non-linear for irradiation times > ca. $100 \mathrm{sec}(36,38)$ (see Fig. 1).

The structure of a glass will generally permit a continuous range of inequivalent sites: we therefore assume that the distribution of rate constants will be continuous. If $N(k, t)$ denotes the number of methyl radicals at time $t$ decaying exponentially with a rate constant between $k$ and $k+d k$, the distribution,

$$
F(k, t)=N(k, t) / \int_{0}^{\infty} N(k, 0) d k
$$

will decay according to,

$$
f(t)=\int_{0}^{\infty} F(k, t) d k=\int_{0}^{\infty} F(k, 0) \exp (-k t) d k .
$$

where $t=0$ denotes the start of the decay. Thus the time dependence $f(t)$ will be the Laplace transform of the initial distribution $F(k, 0)$. This relationship allows us to transform the observed pattern of decay for short irradiation times,

$$
f(t)=\exp \left(-c t^{\frac{1}{2}}\right)
$$



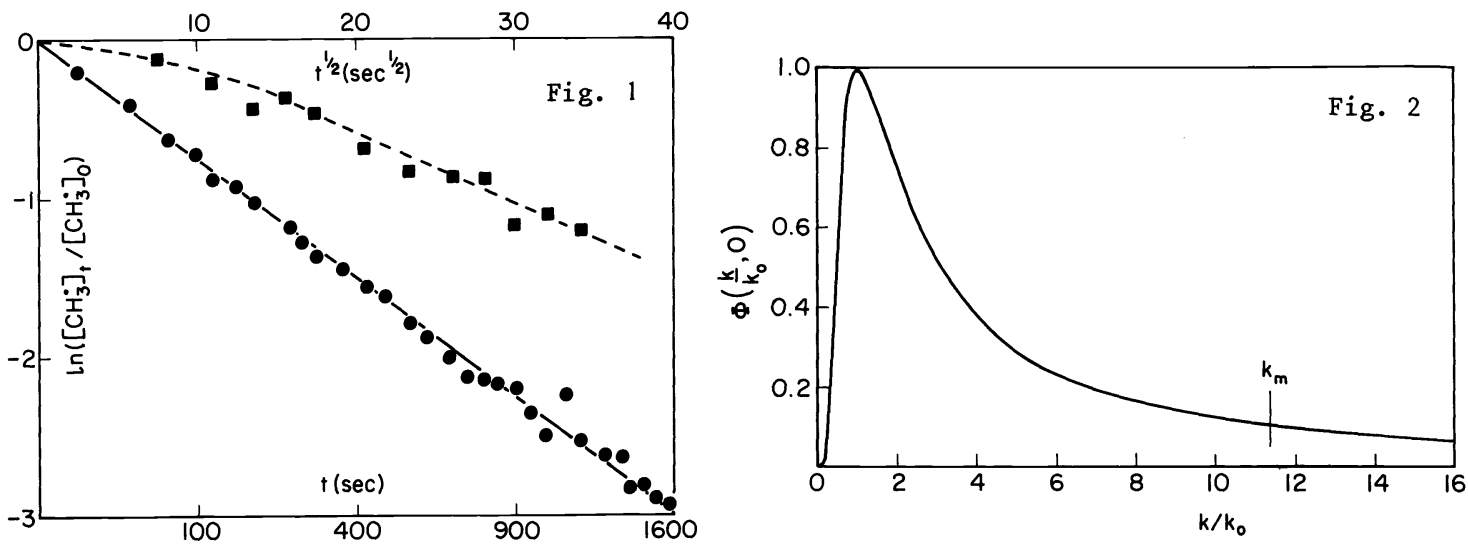

Fig. 1 Decay of the methyl radical in a methanol glass at $77 \mathrm{~K}$. Irradiation times used to generate radicals: $10 \mathrm{sec}\left(\mathrm{O}_{-}\right)$and ca. 10,000 sec (口-.-

Fig. 2 Normalized distribution of rate constants for short irradiation times.

into an initial distribution of rate constants,

$$
F(k, 0)=c\left(4 \pi k^{3}\right)^{-\frac{1}{2}} \exp \left(-c^{2} / 4 k\right)
$$

This function reaches its maximum for $k \equiv k_{0}=c^{2} / 6$. Since there are more sites with $k=$ $k_{0}$ than with any other $k$ value, $k_{0}$ is the "most probable" rate constant, which is smaller than the apparent rate constant by a factor of six. This distribution is depicted in Figure 2 in the normalized form:

$$
\phi\left(\frac{k}{k_{0}}, 0\right)=\frac{F(k, 0)}{F\left(k_{0}, 0\right)}=\left[\frac{k}{k_{0}} \exp \left(\frac{k_{0}}{k}-1\right)\right]^{-3 / 2}
$$

To characterize the distribution further, we can also define a "median" rate constant $k_{m}$ by the condition that the number of sites with $k<k_{m}$ equals that with $k>k_{m}$. We calculate that $k_{m}=11.4 k_{0}$ (see Fig. 2). Incidentally, it is not possible to define mathematically an "average" rate constant (39). This can be understood in terms of the strong asymmetry of the distribution, in particular its long tail which falls off very slowly as $k$ increases.

Fortunately, the distribution can be given a more symmetrical and physically more meaningful form by transforming to a new variable $q=\ell n\left(k / k_{0}\right)$ :

$$
\phi\left(e^{q}, 0\right)=\exp \left[-3 / 2\left(q+e^{-q}-1\right)\right]
$$

This distribution is illustrated in Fig. 3 by the solid curve. Since the rate constant $k$ is expected to vary exponentially with the tunneling distance, the new variable $q$ represents a measure of this distance, and in this form the distribution yields information on the structure of the glass in the neighbourhood of the methyl radical.

For small $q$, this distribution reduces to a Gaussian:

$$
\lim _{q \rightarrow 0} \phi\left(e^{q}, 0\right)=\exp \left(-3 / 4 q^{2}\right)
$$

We have found (39) that such a Gaussian distribution can account for the observed decay law $\exp \left(-c t^{\frac{1}{2}}\right)$, if we drop the conditions that this distribution peaks at $k_{0}=c^{2} / 6$ and has a half width at $1 /$ e of $(3 / 4)^{-\frac{1}{2}}=1.15$. A Gaussian distribution having a half width of ca. 1.3 and a most probable rate constant of ca. $1.3 k_{0}$ will fit our observed rate law within our limits of experimental error. This distribution is shown by the dot-dash curve in Fig. 3. Thus, a Gaussian distribution of tunneling distances represents an acceptable interpretation of our results, though for practical reasons we use the distributions (24) and (25) since their Laplace transform is available in analytical form, which is not the case for the Gaussian distribution. 

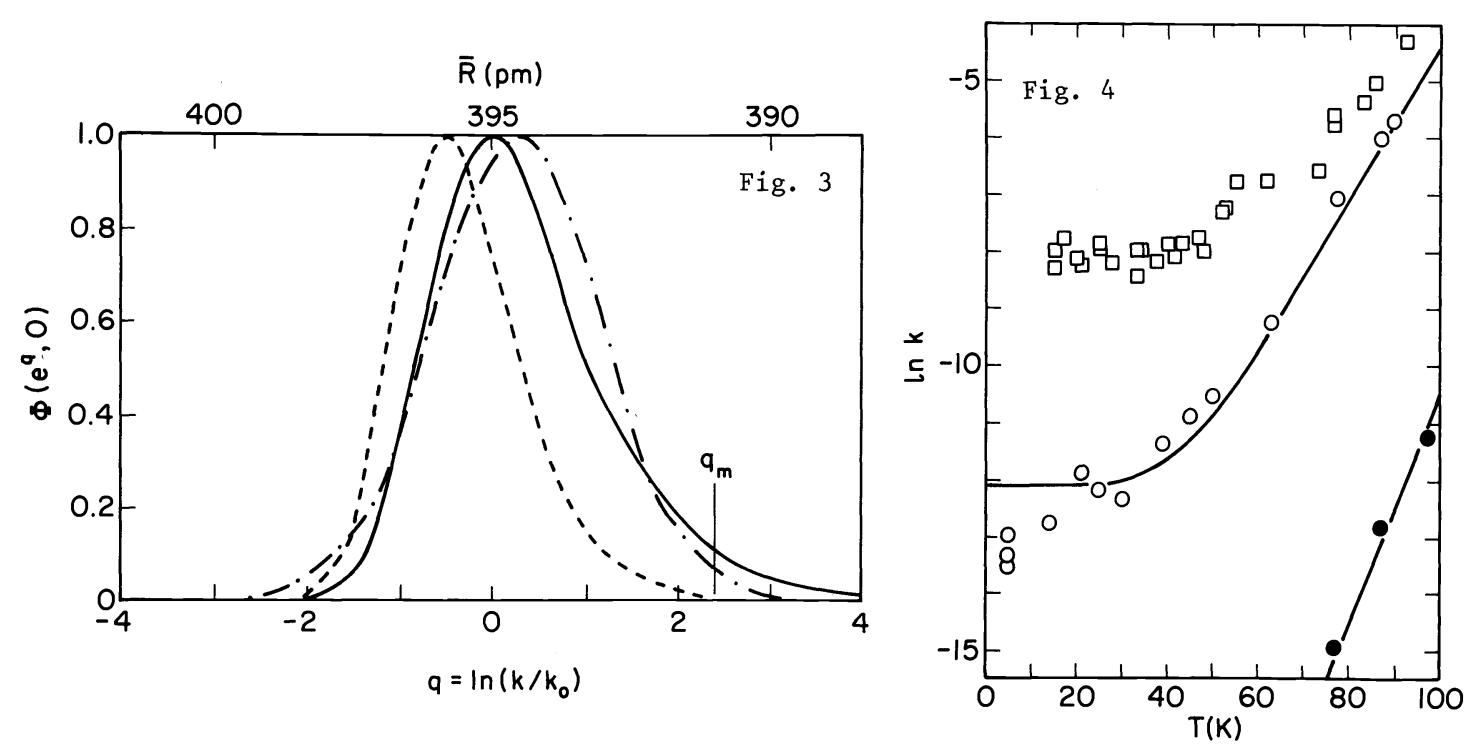

Fig. 3 Distribution of $\mathrm{q}$ values and tunneling distances for the $\mathrm{CH}_{3}^{\circ}+\mathrm{CH}_{3} \mathrm{OH}$ reaction. The solid line represents the initial distribution according to eq. 25 and the dot-dash line, the corresponding Gaussian distribution (see text). The dashed line represents the "steady-state" distribution achieved after prolonged irradiation; it corresponds to the dashed line in Figure 1. The scale of tunneling distances is derived from best-fits of calculated $k(T)$ curves with experiment at $k=$ $k_{0}$ and $k=k_{m}$ (see text).

Fig. 4 Most probable rate constants, $\mathrm{k}$, for the decay of $\mathrm{CH}_{3}$ in $\mathrm{CH}_{3} \mathrm{OH}(0-0)$ and in $\mathrm{CD}_{3} \mathrm{OD}$ (-) glasses. The curves drawn through these points were calculated as described. Squares denote rate constants taken from ref. 33 that were derived from the initial portion of the decay traces with the assumption that $\mathrm{CH}_{3}^{*}$ decay in a $\mathrm{CH}_{3} \mathrm{OH}$ glass follows a simple exponential rate law.

The most probable rate constant, $k_{0}$, or for that matter the median rate constant, $k_{m}$, can be derived directly from the semilogarithmic plot of the $\mathrm{CH}_{3}^{\bullet}$ concentration against $\mathrm{t}^{\frac{1}{2}}$. For short irradiation times our $77 \mathrm{~K}$ kinetic data yield $c=7.3 \times 10^{-2} \mathrm{~s}^{-\frac{1}{2}}$ and hence $\mathrm{k}_{0}=8.9 \times$ $10 \mathrm{~s}^{-1}$. For irradiation times, $\tau$, that are long with respect to methyl radical decay (i.e., $k \tau \gg 1$ ) a "steady-state" distribution of rate constants will be obtained which is narrower and which has a smaller value for the most probable rate constant. This distribution which peaks at $k=0.6 k_{0}$ is illustrated by the dashed line in Fig. 3 . It can be represented by,

$$
F(k, \tau)=(c / \tau)\left(4 \pi k^{5}\right)^{-\frac{1}{2}} \exp \left(-c^{2} / 4 k\right)
$$

which yields the relation

$$
f(t)=\left(2 / c^{2} \tau\right)\left(c t^{\frac{1}{2}}+1\right) \exp \left(-c t^{\frac{1}{2}}\right)
$$

This last equation provides an excellent fit to the data obtained under long irradiation $\left(\tau-10^{4} \mathrm{~s}\right)$ using $c=7.3 \times 10^{-2} \mathrm{~s}^{-\frac{1}{2}}$. Hence, the two different decay patterns shown in Figure 1 can be explained as due to the time evolution of a single rate constant distribution $F(k, 0)$. That is, the non-exponential decay of $\mathrm{CH}_{3}^{\circ}$ in a methanol glass is due to a distribution of rate constants for methyl radicals trapped at different sites.

Since well defined and highly reproducible rate constants could be obtained at $77 \mathrm{~K}$ it immediately became worthwhile to study the reaction over a range of temperatures (40). For short irradiation times and at temperatures < $97 \mathrm{~K}$, semilogarithmic plots of methyl radical concentration against $t^{\frac{1}{2}}$ were linear. This means that the distribution of rate constants and hence, of trapping sites, remains essentially unchanged, $i . e ., k / k_{0}$ is temperature independent. However, values of $k_{0}$ show a profound variation with temperature (see Fig. 4). The rate constants previously derived by Williams et al (33) from the initial part of the decay curve under the assumption that the radical concentration decayed exponentially are very much larger than the most probable rate constants and show a different temperature dependence. Rate constants for the decay of $\mathrm{CH}_{3}^{\circ}$ in $\mathrm{CD}_{3} \mathrm{OD}$ glasses were al so measured (see Fig. 4). 
Thermally activated processes cross a potential energy barrier on their way from the initial to the final state. Classically the rate constant, $k$, for barrier crossing is proportional to the probability of reaching the top of the barrier and hence to a Boltzmann factor relating barrier height to the thermal energy. This argument leads to the Arrhenius equation, $k(T)=A \exp (-E / R T)$. Quantum mechanically, the process is complicated by the possibility of transitions from states below the barrier, namely by tunneling. Empirically, it has been found that curved Arrhenius plots (which can imply a significant contribution to the rate from tunneling) will often yield straight lines if $\log k$ is plotted against $T$ rather than $1 / T$, implying a rate law of the form, $k(T)=A^{\prime} \exp (C T)(33,41,42)$. Although it is possible to choose a barrier shape exhibiting this behavior over a limited temperature range $(33,43)$ these shapes do not compare well with those derived from known molecular properties (38). Thus, although an Eckhart barrier will reproduce the reported rate constants for $\mathrm{CH}_{3}^{\circ}$ decay in methanol glasses reasonably well (33), it does not resemble the barrier constructed from the known $\mathrm{CH}-$ stretching potential for realistic couplings between the relevant carbon atoms (38). The same is true for other "popular" barrier shapes used in tunneling such as the 'truncated' parabolic barrier and gaussian barrier.

The barrier constructed from the known $\mathrm{CH}-$ stretching potentials does not, however, reproduce the observed temperature dependence, but predicts instead a temperature-independent rate constant at temperatures below $200 \mathrm{~K}$ because the excited vibrational levels, which have energies $>3000 \mathrm{~cm}^{-1}$, are not thermally accessible. This indicates that additional degrees of freedom corresponding to lower-frequency motions must be considered. Since not only the $\mathrm{H}$ atom but also the $\mathrm{C}$ atoms carrying it before and after the transfer are in thermal motion, all these motions should be included in the formulation of the transfer rate. Such a model involves tunneling through an "oscillating" barrier which gets narrower and lower as the (low frequency) vibration of the carbon atoms brings them closer together. Such a model in which tunneling occurs through an oscillating barrier will yield a rate law of the form $k(T)=A^{\prime} \exp (C T)$ if the oscillation is assumed harmonic and is treated classically $(41,42,44,45)$.

A more sophisticated and intellectually satisfying quantum mechanical model, which has been developed by Siebrand and coworkers $(46,47)$, can be used to account for the temperature and isotope dependence of the rate constants for methyl radical decay in methanol glasses

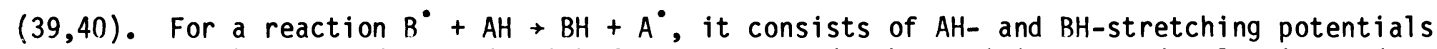
for the bonds broken and formed, with frequency $\omega$ and anharmonicity $x$, and a lattice mode (assumed for simplicity to be harmonic) corresponding to the relative motion of $A$ and $B$, having a low frequency $\Omega$. These vibrations are taken to be adiabatically separable. The potentials are coupled through an intermolecular electronic interaction term $J_{A B}$ which is proportional to the overlap between atomic orbitals centered on $A$ and $B$. Rate constants at different temperatures are then calculated by taking thermal averages over the initialstate quantum numbers and sum over the number of nearest neighbour hydrogen atoms, $n$. Most of the parameters that are known, viz., the $\mathrm{C}-\mathrm{H}(\mathrm{D})$ stretching frequency, $\omega^{\mathrm{H}}=2960 \mathrm{~cm}^{-1}$, $x^{H}=-15 \mathrm{~cm}^{-1}, \omega^{D}=2172 \mathrm{~cm}^{-1}, x^{D}=-8 \mathrm{~cm}^{-1}$; reduced masses for $H(D), m^{H}=0.923 \mathrm{~m}_{0}, \mathrm{~m}^{D}=$ $1.714 \mathrm{~m}_{0}$, and for the $\mathrm{C}-\mathrm{-C}$ oscillators $\mathrm{CH}_{3}--\mathrm{CH}_{3} \mathrm{OH}\left(\mathrm{CD}_{3} \mathrm{OH}\right), \mathrm{M}^{\mathrm{H}}=10.2 \mathrm{~m}_{0}, \mathrm{M}^{\mathrm{D}}=10.6 \mathrm{~m}_{0}$; and the equilibrium $\mathrm{C}-\mathrm{H}$ distance, $\xi=1.09 \AA$. Values of the frequencies $\Omega^{H}$ and $\Omega^{D}$, subject to $\Omega^{H} / \Omega^{D}=\left(M^{D} / M^{H}\right)^{\frac{1}{2}}$, and of the equilibrium distance $\bar{R}$ were adjusted to give the best fit, starting from estimates $\Omega=133 \mathrm{~cm}^{-1}$ (the Debye frequency of ice) and $\bar{R}=400 \mathrm{pm}$ (twice the Van der Waals radius of a methyl group). The exothermicity of the reaction, $\Delta E$, is not known accurately. It is reported to lie in the range $26 \pm 10 \mathrm{~kJ} \mathrm{~mol}^{-1}$ and was adjusted to produce the best fit. The coupling parameter $J(\vec{R})$ was calculated by an ab initio method

(48). The result for $\bar{R}=400 \mathrm{pm}$ was, for example, $J(400)=2450 \mathrm{~cm}^{-1}\left(29 \mathrm{~kJ} \mathrm{~mol}^{-1}\right)$. The number of nearest neighbour $H$ (D) atoms, $n$, was estimated to be 33 . This estimate was based on an experiment in which methyl decay was monitored in a glass consisting of $\mathrm{CH}_{3} \mathrm{OH}$ : $\mathrm{CD}_{3} \mathrm{OD}$ in the ratio $1: 9$. The decay curve of $\mathrm{CH}_{3}^{\circ}+\mathrm{CH}_{3} \mathrm{OH}$, corrected for $\mathrm{CH}_{3}^{\circ}+\mathrm{CD}_{3} \mathrm{OD}$, showed a distribution with a large fraction (33\%) of unreactive radicals, corresponding to $\mathrm{CH}_{3}^{\circ}$ without $\mathrm{a} \mathrm{CH}_{3}$ group in the adjacent solvent shell. From this result, we calculate that on average, eleven methyl groups line the glass cage surrounding each methyl radical, which indicates that the radical is completely surrounded by methanol molecules. Hence the halogen ion produced during radical generation must be separated from the radical. Presumably there is localized rearrangement of the glass which significantly increases the $C-X$ distance using the energy gained by increased solvation of the halogen ion relative to the methyl halide molecule.

The parameters described above were used to calculate $k(T)$ curves. Since the $k$ values form a continuous distribution we select specific values within this distribution. We assume that different sites show different rate constants only because their tunneling distances are different. Since the distribution of tunneling distances (i.e., of q-values) will be temperature independent, we can select any value of $q$ for the calculation of a corresponding $k(T)$ curve. 
The first set of $k(T)$ values was the set for $k_{0}(T)$ corresponding to $q=0$. The "best" fit to the data was obtained with the adjustable parameters given the values: $\Omega^{\mathrm{H}}=130 \mathrm{~cm}^{-1}$, $\overline{\mathrm{R}}_{0}=395 \mathrm{pm}$, and $\Delta \mathrm{E}=24 \mathrm{~kJ} \mathrm{~mol}^{-1}$; values that are all very close to the estimates given above. The resulting $\mathrm{k}_{0}(\mathrm{~T})$ curves for $\mathrm{CH}_{3} \mathrm{OH}$ and $\mathrm{CD}_{3} \mathrm{OD}$ are shown as the solid lines in Fig. 4. They fit the data very well, except that the rate constants for $\mathrm{CH}_{3}^{\bullet}+\mathrm{CH}_{3} \mathrm{OH}$ are overestimated by a factor of up to 3 in the temperature range 5-10 K. Similar calculations were carried out with other values of $q$. For example, for $q=q_{m}=\ln \left(k_{m} / k_{0}\right)=2.43$, a fit of comparable quality was obtained by adjusting $\bar{R}$ to $\bar{R}_{m}=3.91 \mathrm{pm}=\bar{R}_{0}-4 \mathrm{pm}$. These calculations can be used to calibrate the scale of $q$ in picometers, since $q_{m}=2.43$ corresponds to $-4 \mathrm{pm}$. The corresponding scale of $\bar{R}$ values is indicated on the top of Fig. 3 . The width at half-maximum of the distribution $\Phi\left(e^{q}, 0\right)$ is about $3.3 \mathrm{pm}$. The most probable distance of this distribution, i.e., the most probable tunneling distance, is $\bar{R}_{0}-2 \xi=$ $(395-2 \times 109) \mathrm{pm}=177 \mathrm{pm}(39)$.

In summary, the dynamics of $\mathrm{H}$-atom transfer to a methyl radical in a methanol glass can be fairly well reproduced by our model of tunneling through a two dimensional barrier. One dimension, associated with $\mathrm{C}-\mathrm{H}$ stretching accounts for the observed strong $\mathrm{D}$ isotope effect, while the other, associated with a lattice mode, is mainly responsible for the temperature dependence. The good fit obtained with parameter values most of which were independently known or calculated, supports not only this interpretation but also the derived tunneling distances. Except at the lowest temperatures investigated where some deviation is observed, our analysis is consistent with the assumption of freely tumbling radicals and freely rotating methyl groups. The tunneling distance is therefore the only parameter that varies between sites. One very interesting consequence of the absence of orientational effects is that $\mathrm{H}$-atom transfer rates in matrices will be controlled mainly by Van der Waals radi $i$ and should therefore not show much variation between different organic matrices. This is confirmed by some data listed in Table 4. The general conclusions drawn for methyl radicals in methanol should therefore be widely applicable.

TABLE 4. Most probable rate constants, $\mathrm{k}_{0}\left(=\mathrm{c}^{2} / 6\right)$, for $\mathrm{CH}_{3}^{\bullet}$ decay in organic glasses at $77 \mathrm{~K}$ (Decay law: $\left.\ln \left(\left[\mathrm{CH}_{3}^{\bullet}\right]_{\mathrm{t}} /\left[\mathrm{CH}_{3}^{\bullet}\right]_{0}\right)=-\mathrm{ct}^{\frac{1}{2}}\right)$.

\begin{tabular}{lclc}
\hline Matrix & $10^{5} \mathrm{k}_{0}\left(\mathrm{sec}^{-1}\right)$ & \multicolumn{1}{c}{ Matrix } & $10^{5} \mathrm{k}_{0}\left(\mathrm{sec}^{-1}\right)$ \\
\hline $\mathrm{CH}_{3} \mathrm{OH}$ & 89 & Tetrahydrofuran & 62 \\
$\mathrm{C}_{2} \mathrm{H}_{5} \mathrm{OH}$ & $45^{\mathrm{a}}$ & Dimethyl ether & 27 \\
${\mathrm{n}-\mathrm{C}_{3} \mathrm{H}_{7} \mathrm{OH}}^{\mathrm{i}-\mathrm{C}_{3} \mathrm{H}_{7} \mathrm{OH}}$ & $32^{\mathrm{a}}$ & Acetone & 27 \\
$\mathrm{t}-\mathrm{C}_{4} \mathrm{H}_{9} \mathrm{OH}$ & $6^{\mathrm{a}}$ & Trimethylamine & 7 \\
$\left(\mathrm{CH}_{2} \mathrm{OH}\right)_{2}$ & 2 & 1,4 -Dioxane & 2 \\
${ }^{\mathrm{a}} \mathrm{Cal} \mathrm{Culated} \mathrm{from} \mathrm{data}$ in ref. 35. & & 1 \\
& 7 & & \\
\hline
\end{tabular}

Acknowledgement. The research described in this talk could not have succeeded without the enthusiastic, dedicated, and skillful efforts of my co-workers whose names appear in the references.

\section{REFERENCES}

1. "Radical Reaction Rates in Liquids", H. Fischer, Ed., Landolt-Börnstein, New Series, Group II, Springer-Verlag, Berl in, Volumes 13a-d, 1983-84.

2. A.L.J. Beckwith and K.U. Ingold, "Rearrangements in Ground and Excited States", P. de Mayo, Ed., Academic Press, New York, Vol . 1, 161-310 (1980).

3. D. Griller and K.U. Ingold, Acc. Chem. Research, 13 317-323 (1980).

4. J.-M. Surzur, P. Teissier, C.R. Hebd. Seances Acad. Sci, Ser. C 264, 1981-1984 (1967) Bull Soc. Chim. Fr. 3060-3070 (1970). 
5. D.D. Tanner and F.C.P. Law, J. Am. Chem. Joc. 91, 7535-7537 1969).

6. A.L.J. Beckwith and P.K. Tindal, Aust. J. Chem. 24, 2099-2116 (1971).

7. A.L.J. Beckwith and C.B. Thomas, J. Chem. Soc., Perkin Trans. 2 861-872 (1973).

8. L.R.C. Barclay, D. Griller and K.U. Ingold, J. Am. Chem. Soc. 104, 4399-4403 (1982).

9. L.R.C. Barclay, J. Lusztyk and K.U. Ingold, J. Am. Chem. Soc. 106, 1793-1796 (1984).

10. S. Saebo, A.L.J. Beckwith and L. Radom, J. Am. Chem. Soc. in press.

11. W.H. Urry and M.S. Kharasch, J. Am. Che. Soc. 66, 1438-1440 (1944).

12. B. Maillard and K.U. Ingold, J. Am. Chem. Soc. 98, 1224-1226, 4692 (1976).

13. K.U. Ingold and J. Warkentin, Can. J. Chem. 58, 348-352 (1980).

14. C. Chatgilialoglu, K.U. Ingold, I. Tse-Sheepy and J. Warkentin, Can. J. Chem. 61, 1077-1081 (1983).

15. D.A. Lindsay, J. Lusztyk and K.U. Ingold, submitted to J.Am. Chem. Soc.

16. J.A. Franz, R.D. Barrows and D.M. Camaioni, J. Am. Chem. Soc. in press.

17. C. Chatgilialoglu, K.U. Ingold and J.C. Scaiano, J. Am. Chem. Soc. 103, 7739-7742 (1981).

18. D.J. Carlsson and K.U. Ingold, J. Am. Chem. Soc. 90, 7047-7055 (1968).

19. C. Chatgilialoglu, K.U. Ingold and J.C. Scaiano, J. Am. Chem. Soc. 104, 5123-5127 (1982).

20. K.U. Ingold, J. Lusztyk and J.C. Scaiano, J. Am. Chem. Soc. 106, 343-348 (1984).

21. L.H. Summer and L.A. Ull and, J. Org. Chem. 37, 3878-3861 (1972).

22. K. Mochida, T. Yamaguchi and H. Sakurai, J. Organomet. Chem. in press.

23. L.J. Johnston, J.C. Scaiano and K.U. Ingold, submitted to J. Am. Chem. Soc.

24. L.J. Johnston, unpublished results.

25. G. Brunton, D. Griller, L.R.C. Barclay and K.U. Ingold, J. Am. Chem. Soc. 98, 6803$6811(1976)$.

26. G. Brunton, J.A. Gray, D. Griller, L.R.C. Barclay, K.U. Ingold, J. Am. Chem. Soc. $100,4197-4200$ (1978).

27. V. Malatesta and K.U. Ingold, J. Am. Chem. Soc. 103, 3094-3098 (1981).

28. M. Anpo, C. Chatgilialoglu and K.U. Ingold, J. Org. Chem. 48, 4104-4106 (1983).

29. T. Doba and K.U. Ingold, J. Am. Chem. Soc., in press.

30. S.W. Benson, Thermochemical Kinetics, 2nd Ed., Wiley, New York (1976).

31. A. Campion and F. Williams, J. Am. Chem. Soc., 94, 7633-7637 (1972).

32. R.L. Hudson, M. Shiotani and F. Williams, Chem. Phys. Letters, 48, 193-196 (1977).

33. R.J. LeRoy, H. Murai and F. Williams, J. Am. Chem. Soc., 102, 2325-2334 (1980).

34. B.V. Bol'shakov and V.A. Tolkatchev, Chem. Phys. Letters, 40, 468-470 (1976).

35. A.A. Stepanov, V.A. Tkatchenko, V.B. Bol'shakov and V.A. Tolkatchev, Intern. J. Chem. Kinetics, 10, 637-648 (1978).

36. V.B. Bol'shakov, A.B. Doktorov, V.A. Tolkatchev and A.I. Burshtein, Chem. Phys. Letters, 64, 113-115 (1979).

37. B.V. Bol'shakov, A.A. Stepanov and V.A. Tolkatchev, Intern. J. Chem. Kinetics, 12, 271-281 (1980).

38. T. Doba, K.U. Ingold and W. Siebrand, Chem. Phys. Leters, 103, 339-342 (1984).

39. T. Doba, K.U. Ingold, W. Siebrand and T.W. Wildman, Unpublished resuls.

40. T. Doba, K.U. Ingold, W. Siebrand and T.W. Wildman, submitted to J. Phys. Chem.

41. W.R. McKinnon and C.M. Hurd, J.Phys. Chem., 87, 1283-1285 (1983).

42. V.A. Benderskii, V.I. Goldanskii and A.A. Ovchinnikov, Chem. Phys. Letters, 73, 492495 (1980).

43. R.J. LeRoy, J. Phys. Chem., 84, 3508-3516 (1980).

44. R.H. Tredgold, Proc. Phys. Soc. (London), 80, 807-810 (1962).

45. L.I. Trakhtenberg, V.I. Klochkin and S. Ya. Pshezhetskii, Chem. Phys., 69, 121-134 (1982).

46. W. Siebrand, T.A. Wildman and M.Z. Zgierski, Chem. Phys. Letters, 98, 108-112 (1983).

47. W. Siebrand, T.A. Wildman and M.Z. Zgierski, J. Am. Chem. Soc., in press.

48. T.A. Wildman, unpublished results. 